\title{
EVALUATION OF COMPLIANCE OF EXISTING FOREST MACHINE INFORMATION SYSTEMS FOR THE IMPLEMENTATION OF THE STANDARD STANFORD 2010
}

\author{
*Aigars Strubergs ${ }^{1}$, Andis Lazdins ${ }^{2}$, Linards Sisenis ${ }^{1}$ \\ ${ }^{1}$ Latvia University of Life Sciences and Technologies, Latvia \\ ${ }^{2}$ Latvia State Forest Research Institute 'Silava', Latvia \\ *Corresponding author’s email: aigars.strubergs@1lu.lv
}

\begin{abstract}
The aim of the study is to clarify the compliance of machinery information systems used by Latvian logging service providers with the requirements of the Forest Machine Data and Communications Standard StanForD 2010. For determining the number of logging machines and structure registered in Latvia, data from the State Technical Control Agency of Latvia (VTUA) has been used. This dataset includes 2094 registered machinery units from which 1663 units recorded as harvesters and forwarders are distributed for data processing. Using the national AS Latvian State Forests (LSF) database, where 541 machinery units have been recorded, of which 239 harvesters and 302 forwarders, it is determined what and how many machines already use the standard StanForD 2010, how many machines can implement it and which machines are not suitable for the implementation of StanForD 2010. The study showed that the VTUA register does not fully reflect the true quantity of harvesting machines in Latvia and does not provide information about the use of machines. The LSF data provide reliable information on the possibilities of using StanForD 2010 in harvesters in national forests. From the harvesters working in the country's forests, $52 \%$ of the machines uses the StanForD 2010 standard. Work should be continued to clarify the possible use of the standard in the machines working in private forests. Similarly, work should be continued with dealers of harvesting machines to identify models for which it is possible to adjust the StanForD 2010 standard and what the cost of adapting the indicative information systems is.
\end{abstract}

Key words: forest harvesting, StanForD 2010, efficiency.

\section{Introduction}

In recent decades, Scandinavian or, in other words, assortment technology is widely applied in logging all over the world. With this technology, logging takes place using two types of machines: harvesters (cut-to-length - CTL), which carry out felling, delimbing and bucking in the assortments on the felling site and forwarders of a certain length that take these assortments from the felling site to the top yard. When a certain amount of assortments has been loaded in the yard, the delivery of the assortments is organised to the bottom-end yard or processing company with timber trucks. Therefore, the circulation of exact information between the provider of logging services, round wood transporters and contractors is becoming very current.

As information technologies and their applications evolve, such development has also influenced harvesting machines. The development began in the eighties when Robert Bosch $\mathrm{GmbH}$ developed and began introducing CAN (Cartoon Area Network) into the management of technology machines (CAN in Automation, 2011). Later CAN technology was used in logging machines to automatically record machine parameters when work was done, without direct human participation. Automatic data recording can also result in more accurate accounting of machine and operator working time, reducing the need for manual working time accounting and improving its accuracy as machines become faster and conduct work time records manually, a researcher can no longer track all activities such as indicate the average of the sawn tree and species (Peltola, 2003). For such records a special data logger connected to the machine control system by a CAN cable was developed for. In the mid-eighties, machine data communication standard StanForD was developed specifically for logging machines, it collected data of machines, products and a series of other data, and was important for machine and human work analysis at that time. The development of harvesting machines and information systems is demonstrated in Table 1 (Palander et al., 2013).

Each logging machine manufacturer had developed its own control systems according to the StanForD standard for data file processing, hence, to process the machine data, such programs needed to be purchased from the machinery manufacturer. In most cases, the software of different manufacturers is completely or partially incompatible, which makes the processing of data from different manufacturer programs quite difficult. The problem also arises when a harvesting company has purchased and operates several manufacturer harvesting machines, then data processing requires each manufacturer's data processing programs and additional purchasing of manufacturers' licenses. In addition, programs may have limitations on data processing and storage. Of course, you can transfer data into a .pdf format, however, with such a large amount of data, the processing can be time consuming and these files are not usable for further automated data processing.

Over time, the first version of StanForD became outdated, many variables lost their relevance and there was a need for other content data. In 2010 a new 
The development of time studies in harvester operations (Palander et al., 2013)

\begin{tabular}{|c|c|c|c|c|c|}
\hline & \multicolumn{5}{|c|}{ Decades } \\
\hline & 1970’s & 1980’s & 1990’s & 2000’s & 2010’s \\
\hline \multicolumn{6}{|l|}{ Timing Techniques } \\
\hline \multicolumn{6}{|l|}{ Digital watch } \\
\hline \multicolumn{6}{|l|}{ Field computer } \\
\hline \multicolumn{6}{|l|}{ Video technique } \\
\hline \multicolumn{6}{|l|}{ Automated data collector } \\
\hline \multicolumn{6}{|l|}{ Research Topic } \\
\hline \multicolumn{6}{|l|}{ Machine technology } \\
\hline \multicolumn{6}{|l|}{ Determination of piecework rates } \\
\hline \multicolumn{6}{|l|}{ Cutting environment } \\
\hline \multicolumn{6}{|l|}{ Harvester - forwarder team } \\
\hline \multicolumn{6}{|c|}{ Operators skills in man - machine systems } \\
\hline \multicolumn{6}{|l|}{ Time Study Approaches } \\
\hline \multicolumn{6}{|l|}{ Nomenclature } \\
\hline \multicolumn{6}{|l|}{ StanForD } \\
\hline \multicolumn{6}{|l|}{ Process - data models } \\
\hline Adaptive work study methods & & & & & \\
\hline
\end{tabular}

StanForD 2010 standard was finished and introduced (Arlinger et al., 2012). The new standard works in an open .xml format and no special, expensive program is required to open a file. Changes in the file types compared to the old standard are large because it was based on felling, while the new one is based on a time scale that allows a much more accurate analysis of the data.

Latvian logging companies have started the implementation of StanForD 2010 and are learning its capabilities. Evaluating research by scientists from other countries, it is clear that the implementation of the standard and, in particular, the scope of application, is in need of a lot of work. The study of research results shows that StanForD 2010 may be successfully used in the analysis of productivity of harvester operator and machine utilization rate, and the automatically acquired data is reliable because studies have shown that differences from manually derived data are not significant (Brewer et al., 2018). Consequently, the analysis of the data obtained can make a significant contribution to improvement of operator skills, hence the productivity would increase and harvesting costs decrease (Strandgard, Walsh, \& Acuna, 2012).

According to State Joint Stock Company Latvian State Forests (LSF) data the forwarders used in Latvia are not using StanForD 2010. However, a literature review reveals that StanForD 2010 data are used in the world to analyse productivity of forwarder operators (Eriksson \& Lindroos, 2014; Manner et al., 2016).
The aim of this study is to assess the readiness of the Latvian Logging Park to implement the StanForD 2010 standard and to identify priority actions for ensuring technical readiness in private and state owned forests.

\section{Materials and Methods}

Data from the State Technical Control Agency of Latvia (VTUA) and from the LSF are used for the analysis of harvesting machines used in Latvia. A survey of Latvia's most popular harvesting machine brand dealer is conducted to clarify the conformity of different models to the standard StanForD 2010.

All purchased or purchased overseas and transported equipment units are recorded in Latvia. The register includes the following information: a machine type, brand, model, factory number, release year, engine power registration date, and details of owner and holder (legal person or private person). Tractor units are removed from the register if they are written off or sold abroad. In Latvia, legislation does not provide an annual technical inspection of harvesting machines, hence the VTUA does not have the data required for the study of how many hours the machine works per year, which would give information whether their machine works or not, and whether this machine exists in Latvia at all.

Data collected from VTUA are used to identify the total number and structure of logging machines recorded in Latvian enterprises or to individuals 
(harvester, forwarder, skidder, etc.). Harvesting machines in the form of a chart are divided by the decades of relese years, determining the age structure of the machine model lines, which allows to discuss the possibilities of implementing StanForD 2010. Next, the machines from this database recorded in Latvia, are grouped by machine type (harvesters, forwarders, u.t.t) and according to their readiness for the implementation of StanForD 2010. In this study, compliance with the implementation of StanForD 2010 will be evaluated only for harvesters. Information on forest machinery registered at VTUA till November 30. 2019 is used in the study.

Using the LSF service provider database (updated in 01 February 2020) the structure of machinery used in harvesting can be determined by brands and model lines. The LSF database provides information about machine type (harvester, forwarder), brand, model, release year, in which type of felling it works (main, tending, damaged tree felling); for harvesters additionally: if it supports StanForD 2010 or not. This information provides an idea of actual workload of harvesting machine that can also be attributed to private forests, creating a picture of the amount of machinery used in harvesting. Based on calculations, different harvesting machines work in private and state forests, meaning, double amount needs twice as many machines. Harvesters are separately divided by brand, each brand is divided by release year, and the release year determines how many machines of each brand support or already use the StanForD 2010 standard.

Surveying of dealers of logging machines was clarified, from which release year an update of information systems can be carried out for each brand according to the StanForD 2010 standard.

Results and Discussion

Using the logging machinery database recorded by VTUA, it has been established that 2094 harvesting machinery units have been recorded on November 30. 2019 in Latvia, including: harvesters, forwarders, skidders and agricultural tractors transferred to forwarders. The oldest machinery unit recorded as a forest machine in VTUA records was produced in 1959. Analysing recorded logging machines by release decades shows that $0.4 \%$ of recorded machines were produced from 1959 to $1970,3.4 \%$ of machines were produced from 1971 to $1980,21.1 \%$ of machines were produced from 1981 to $1990,14.0 \%$ of machines were produced from 1991 to $2000,35.8 \%$ of machines were produced from 2001 to 2010 and $25.3 \%$ of machines were produced from 2011 to 2019 (Figure 1).

When grouping the machines by type, it has been found that 1132 forwarders have been recorded in Latvia, of which the oldest was manufactured in 1959 , and 531 harvesters, of which the oldest was produced in 1988, 2 harwarders and 428 other forest machines with no type specified.

The database of logging machines recorded by VTUA is not an objective data source for the analysis of machines working in Latvia, because a large part, especially the oldest machines may have been dismantled, unused but not removed from the records. However, some middle-aged and younger machines are not used in connection with significant technical damage, may have been rented to other companies in Latvia or abroad and are located outside the territory of Latvia, while preserving registration in Latvia. Therefore, the exact number of harvesting machines in Latvia cannot be estimated. Similarly, it is not in all cases possible to obtain accurate information from the database about what type and brand logging machine has been recorded because only the release year and the type, forest machine, is mentioned. Information is incomplete for both old and last decade produced machines. It is also not possible to obtain information from the VTUA registration data if these machines are supported by the StanForD 2010 standard. It shall be ascertained after the release year and the machine factory number at the dealership of the specific machine.

The distribution of harvesters recorded by VTUA by machine brands (Figure 2).

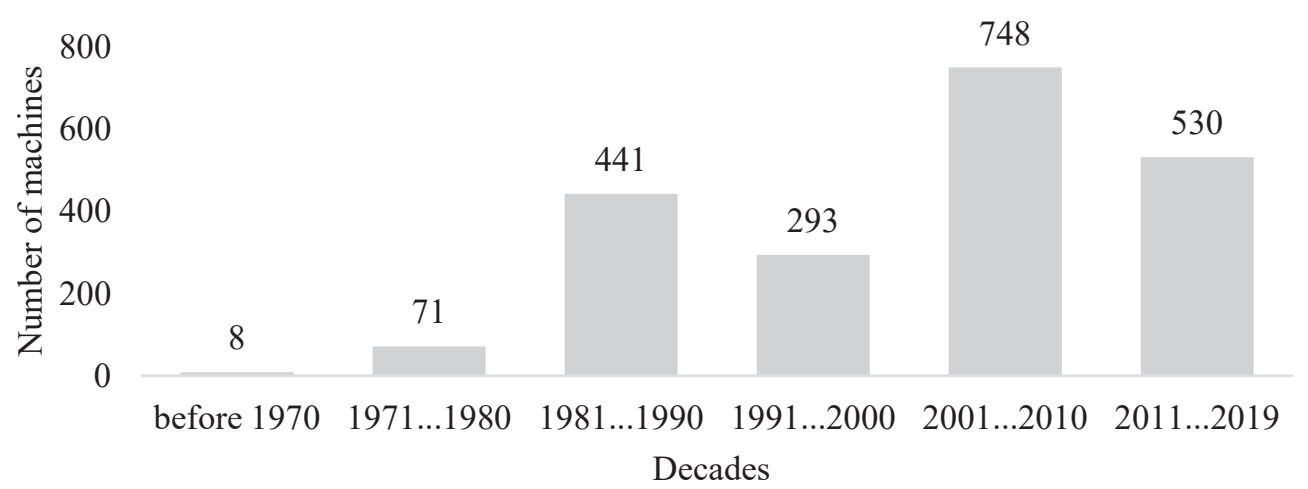

Figure 1. Distribution of logging machines recorded in Latvia by decades of the release. 


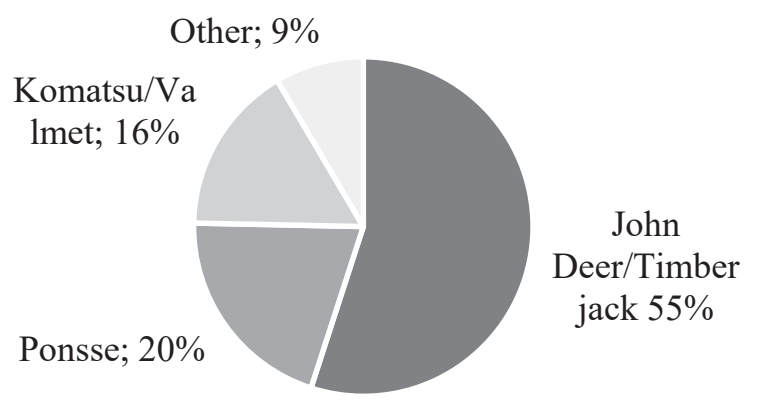

Figure 2. Distribution of harvesters by machine brands.

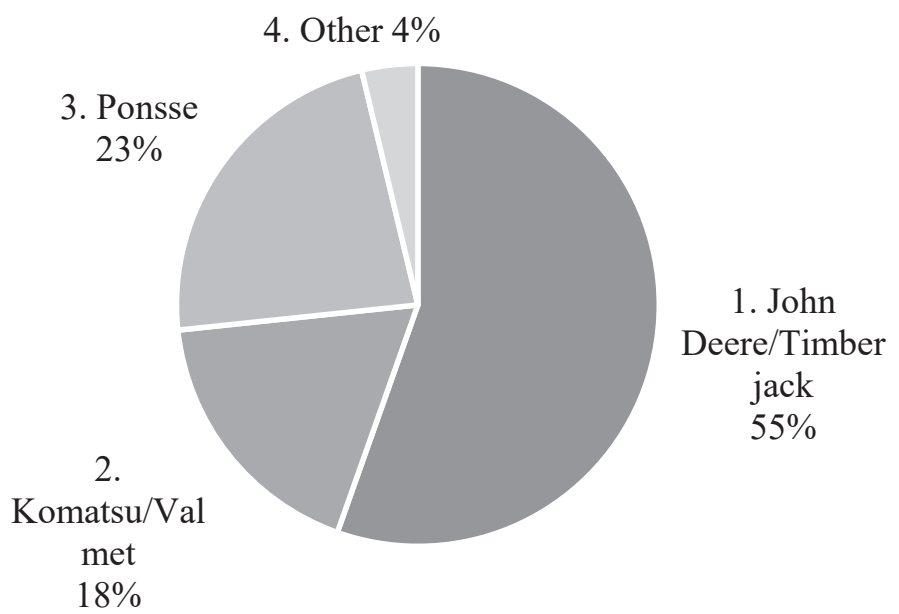

Figure 3. Distribution of harvesters by manufacturers.

Given that the harvesting amount and structure in cutting types in private and state owned forests is comparable, more accurate information on actually used harvesting machines in the country can generally be obtained by assessing which harvesting machines are used in LSF felling areas.

Using LSF data on machinery units involved in harvesting operations, information is obtained on how and what harvesting machines are already working by using the StanForD 2010 standard and what is the potential application structure of harvesting machines in private forests. During this extrapolation, thinning and final felling are analysed separately. The State Forest Service data on logging in state and other forests from 2015 to 2020 years have been used to analyse harvesting volume.

LSF StanForD 2010 data are used for production records and harvester .hpr and .hqr files are applied to the harvester quality control. In this regard, there is a lack of reasonable information to what extent such information is used by private forest owners.

According to LSF data in areas managed by the company, logging companies working on contract basis use 239 harvesters and 302 forwarders. According to the information provided by LSF, the StanForD 2010 standard is used only in harvester reports.

The distribution of the harvesters working in LSF by manufacturers is illustrated in Figure 3. Most widely used are John Deere/Timberjack harvesters 133 machinery units, followed by Ponsse harvesters 54 machinery units, Komatsu/Valmet harvesters 43 machinery units and $4 \%$ of other manufacturers machinery including three Logset harvesters, two Ecolog harvesters and one of each by Jacrac, Case, Rottne and Vimek.

From the 239 harvesters used in LSF harvesting, the StanForD 2010 standard is supported by 125 machines (Figure 4). Looking at the distribution of harvesters by manufacturers and support of StanForD 2010, it is evident that LSF harvesting companies conduct work with 133 John Deere/Timberjack harvesters of which 72 supports StanForD 2010, 54 Ponsse harvesters of which the standard is supported by 32 machines, while from 43 Komatsu/Valmet machines standard is supported by 17 .

As each machine brand has its own management system and software, the analysis needs to look at each brand of the machine separately. 


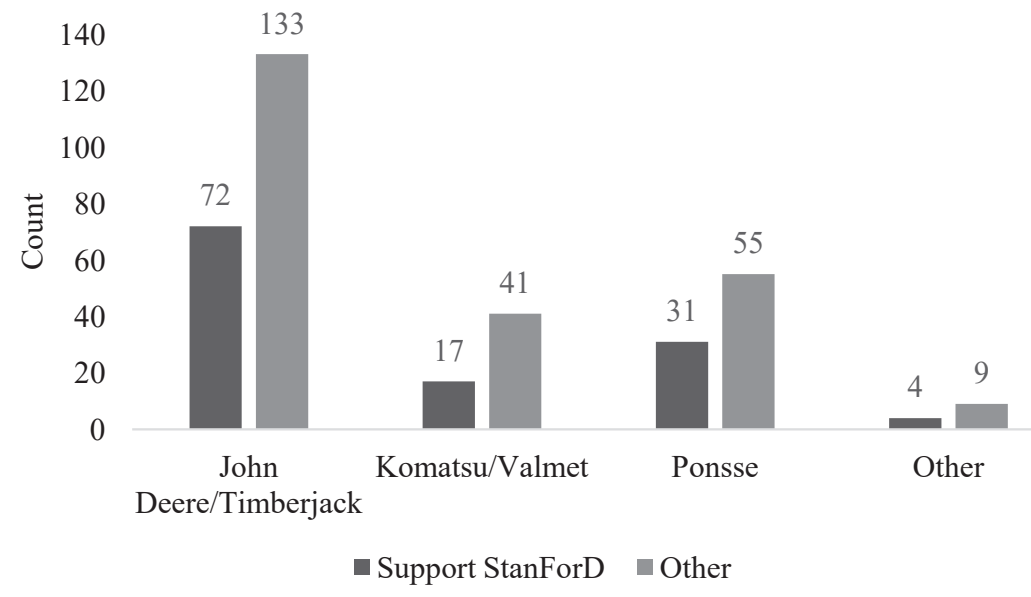

Figure 4. Harvester distribution by manufacturer and StanForD 2010 support (units).

The most popular brands offorest machines in Latvia (John Deer/Timberjack, Ponsse and Komatsu/ Valmet) are evaluated in the study. Distribution of machines of the brands by the release year and information on the support to StanForD 2010 is provided in Table 2.

Logging machines were equipped with systems supporting StanForD 2010 standard in factory starting from the model year 2009-2010. According to Figure 4 and Table 2, LSF employs 229 John Deere / Timberjack, Ponsse and Komatsu / Valmet harvesters and 120 or $52 \%$ of them supports the StanForD 2010 standard. LVM employs 152 harvesters manufactured after 2009, including 96 harvesters (63\%) with information systems supporting StanForD 2010 standard. A survey of equipment dealers demonstrated

Distribution of harvesters (number of units) of the most popular brands by production years

\begin{tabular}{|c|c|c|c|c|c|c|}
\hline \multirow[b]{2}{*}{ Model year } & \multicolumn{2}{|c|}{ John Deere/Timberjack } & \multicolumn{2}{|c|}{ Ponsse } & \multicolumn{2}{|c|}{ Komatsu/Valmet } \\
\hline & Count & $\begin{array}{l}\text { Support } \\
\text { standart }\end{array}$ & Count & $\begin{array}{l}\text { Support } \\
\text { standart }\end{array}$ & Count & $\begin{array}{l}\text { Support } \\
\text { standart }\end{array}$ \\
\hline 2000 & 1 & - & - & - & - & - \\
\hline 2001 & - & - & - & - & 1 & - \\
\hline 2002 & - & - & 1 & - & - & - \\
\hline 2003 & 1 & - & - & - & - & - \\
\hline 2004 & 2 & 1 & - & - & 1 & - \\
\hline 2005 & 4 & - & 2 & - & 3 & - \\
\hline 2006 & 14 & 2 & 1 & - & 4 & - \\
\hline 2007 & 12 & 3 & 4 & - & - & - \\
\hline 2008 & 14 & 5 & 3 & - & 3 & 1 \\
\hline 2009 & 7 & 4 & 3 & 1 & - & - \\
\hline 2010 & 13 & 10 & 1 & - & 1 & 1 \\
\hline 2011 & 9 & 7 & 4 & - & 7 & 2 \\
\hline 2012 & 9 & 6 & 3 & - & 5 & 3 \\
\hline 2013 & 6 & 6 & 2 & 2 & - & - \\
\hline 2014 & 9 & 7 & 3 & 2 & 6 & 4 \\
\hline 2015 & 3 & 2 & 3 & 3 & 4 & 2 \\
\hline 2016 & 7 & 5 & - & - & 2 & - \\
\hline 2017 & 3 & 2 & 6 & 4 & - & - \\
\hline 2018 & 3 & 2 & 8 & 8 & - & - \\
\hline 2019 & 9 & 9 & 11 & 11 & 4 & 4 \\
\hline
\end{tabular}


that each brand of harvesters manufactured after 2009 may have different costs for updating the information system. The final cost depends on the amount of work to be performed and depends on the equipment of the harvester. Harvester information systems are constantly being developed and improved, so software updates are needed. For harvesters after 2015, a software update is usually sufficient, while harvesters manufactured between 2009 and 2014 may require a software replacement. For harvesters manufactured before 2009, not all brands will have a technically feasible and cost-effective adaptation of the information system to support StanForD 2010. For these harvesters, upgrading the system will include replacing the computer, control unit, and wiring.

The Table 2 shows that most of the LSF working harvesters, or $52 \%$ of the 2010 model year, are supported by StanForD 2010. Survey of the machinery dealers, concludes the most popular harvester brands used in Latvia, which are on average younger than 2010 , require relatively little changes in the software StanForD support.

As logging amounts in public and private forests are similar and $44 \%$ of the harvesters recorded in VTUA work in the state forests, it can be assumed that some of the other harvesters work in private forests and older harvesters are not used at all. If in the national forests after the release year 2009, $37 \%$ of the working machines need software update, it can theoretically be assumed that, at the same harvesting amounts, the software update of harvesters working in private forests is required by the same percentage of machines.

\section{Conclusions}

1. Stanford 2010 is supported by the majority of harvesters produced after 2009 (44\% of the total number of registered harvesters), and for this machine category it is sufficient to update or replace the software in order to ensure standard compliance, accordingly, with the lowest costs. The assessment of the compliance of older harvesters points to a great uncertainty. Machinery units that can theoretically support StanForD 2010 need a replacement of the information system, unless it has already been done.

2. State Technical Control Agency of Latvia shall have information on the logging machines at its disposal, that reflects the general technical characteristics of the machines registered in Latvia (brand, model line, age), which gives an estimate of the number of harvesters supporting StanForD 2010, but this system does not include information on the use of machines and their actual location.

3. According to the harvester records working in Latvian State Forests fellings, 52\% of the machinery units support the StanForD 2010 standard, but in most machinery units this standard support programme is not used or not fitted. Accordingly, Latvian State Forests service providers need a significant contribution of resources and work hours to implement StanForD 2010 in production.

4. The study shows that nearly all of the most popular brand harvesters recorded in Latvia are suitable for the implementation of StanForD 2010, but in order to objectively describe the suitability of harvesters working in private forests for the implementation of StanForD 2010, further research is required.

\section{References}

Arlinger, J., Möller, J., Sorsa, J.A., \& Räsänen, T. (2012). Introduction to StanForD2010. Structural descriptions and implementation recommendations. Skogforsk. 74 p. [Published draft]. Retrieved February 20, 2020, from https:/www.skogforsk.se/contentassets/1a68cdce4af1462ead048b7a5ef1cc06/stanford-2010introduction-150826.pdf.

Brewer, J., Talbot, B., Belbo, H., Ackerman, P., \& Ackerman, S. (2018). A comparison of two methods of data collection for modelling productivity of harvesters: manual time study and follow-up study using onboard-computer stem records. Annals of Forest Research, 61(1), 109-124. DOI: 10.15287/afr.2018.962.

CAN in automation (2011). CAN history. Retrieved February 28, 2020, from https:/www.can-cia.org/canknowledge/can/can-history/.

Eriksson, M., \& Lindroos, O. (2014). Productivity of harvesters and forwarders in CTL operations in Northern Sweden based on large follow-up datasets. International Journal of Forest Engineering. 25 (3), 179-200. DOI: $10.1080 / 14942119.2014 .974309$.

Manner, J., Palmroth, L., Nordfjell, T., \& Lindroos, O. (2016). Load level forwarding work element analysis based on automatic follow-up data. Silva Fennica, Vol. 50. No. 3, article id. No. 1546. 19 p. DOI: 10.14214/ sf. 1546 .

Palander, T., Nuutinen, Y., Kariniemi, A., \& Väätäinen, K. (2013). Automatic Time Study Method for Recording Work Phase Times of Timber Harvesting. Forest Science. Vol. 59, Issue 4, 472-483. DOI: 10.5849/ forsci.12-009.

Purfürst, F.T. (2010). Learning curves of harvester operators. Croatian Journal of Forest Engineering, 31, 89-97. 
Peltola, A. (2003). IT-time for Mechanised Forest Work Study. 2nd Forest Engineering Conference 12-15 May 2003, Växjö, Sweden. Skogsforsk Arbetsrap. 536, 107-112.

Strandgard, M., Walsh, D., \& Acuna, M. (2012). Estimating harvester productivity in Pinus radiata plantations using StanForD stem files. Scandinavian Journal of Forest Research. Vol. 28, Issue 1, 73-80. DOI: 10.1080/02827581.2012.706633. 